\title{
Kombinasi Massage Nape dan Teknik Marmet terhadap Percepatan Pengeluaran ASI pada Ibu Post Partum
}

\section{Combination of Massage Nape and Technique Marmet on The Acceleration of Expenditure ASI Post Partum}

\author{
Endah Tri Wahyuni ${ }^{1}$, Ratna Wulan Purnami ${ }^{2}$ \\ Prodi Kebidanan, STIKes Madani Yogyakarta, Indonesia
}

\section{ARTICLE INFO}

\section{Article history}

Received date

07 August 2020

Revised date

12 August 2020

31 August 2020

05 Sept 2020

Accepted date

11 Sept 2020

\section{Keywords:}

Acceleration of

Expenditure ASI;

Massage Nape;

Technique marmet.

\section{Kata kunci:}

Percepatan pengeluaran

ASI;

Massage Nape;

Teknik marmet.

\author{
ABSTRACT/ ABSTRAK
}

WHO in 2016 still shows the average rate of exclusive breastfeeding (ASI) in the new world is around 38\%. In Indonesia, although a large number of women (96\%) breastfeed their children in their lifetime, only $42 \%$ of babies under 6 months of age are exclusively breastfed. By the time children approach their second birthday, only 55\% are still being breastfed. When compared with the WHO target of 50\%, this figure is still far from the target. Maximum achievement can be applied by applying nape and marmot massage techniques for postpartum mothers so that breast milk can be released more quickly. This study aims to help and explain the combination of nape and marmet massage techniques to speed up the use of breast milk in postpartum mothers in the working area of Ngaglik II Sleman Health Center. This research is Quasi-Experimental research using quantitative and post-test designs, with a sample of 30 respondents divided into groups given intervention and control groups taken by purposive sampling. Univariate and bivariate data analysis. The results showed that the effect of nape massage combination and guinea pig technique on the acceleration of ASI use based on the Mann Whitney Test statistical test showed results (p-value 0,002$)<0,05$. The combination of nape massage and marmet technique has an effect on accelerating breastfeeding.

Data WHO tahun 2016 masih menunjukkan rata-rata angka pemberian ASI eksklusif di dunia berkisar 38\%. Di Indonesia meskipun sejumlah besar perempuan (96\%) menyusui anak mereka dalam kehidupan mereka, hanya 42\% dari bayi yang berusia di bawah 6 bulan yang mendapatkan ASI eksklusif. Pada saat anak-anak mendekati ulang tahunnya yang ke dua, hanya 55\% yang masih diberi ASI. Jika dibandingkan dengan target WHO yang mencapai 50\%, maka angka tersebut masihlah jauh dari target Pencapaian yang optimal tersebut dapat dicapai salah satunya dengan menerapkan massage nape dan teknik marmet pada ibu post partum agar pengeluaran ASI lebih cepat keluar. Penelitian ini bertujuan untuk mempelajari dan menjelaskan bagaimana efektivitas kombinasi massage nape dan teknik marmet terhadap percepatan pengeluaran ASI pada ibu post partum di wilayah kerja Puskesmas Ngaglik II Sleman. Penelitian Quasi Eksperimental dengan pendekatan kuantitatif dan rancangan post-test, dengan jumlah sampel sebanyak 30 responden yang dibagi menjadi kelompok yang diberikan intervensi dan kelompok kontrol yang diambil secara purposive sampling. Analisis data univariat dan bivariat. Hasil penelitian menunjukkan, efek kombinasi massage nape dan teknik marmet terhadap percepatan pengeluaran ASI menurut uji statistik Mann Whitney Test didapatkan hasil ( $p$-value 0,002)<0,05. Kombinasi massage nape dan teknik marmet berpengaruh terhadap percepatan pengeluaran ASI.

Corresponding Author:

Endah Tri Wahyuni

Prodi Kebidanan, STIKes Madani Yogyakarta, Indonesia

Email: endahtri19@yahoo.com 


\section{PENDAHULUAN}

Organisasi Kesehatan Dunia (WHO)/ World Health Organization merekomendasikan agar bayi lahir mendapat ASI Eklusif (tanpa tambahan apa-apa) selama enam bulan sebab ASI adalah nitrisi alamiah terbaik bagi bayi dengan kandungan gizi paling sesuai untuk pertumbuhan optimal. UNICEF menegaskan bahwa bayi yang diberi susu formula memiliki kemungkinan pada bulan pertama kelahirannya dan kemungkinan bayi yang diberi susu formula meninggal dunia 25 kali lebih tinggi dari pada bayi yang disusui oleh ibunya secara ekslusif (Pusat Data dan Informasi Kementrian Kesehatan RI., 2014).

Data WHO tahun 2016 masih menunjukkan rata-rata angka pemberian ASI eksklusif di dunia baru berkisar 38\%. Di Indonesia meskipun sejumlah besar perempuan (96\%) menyusui anak mereka, hanya $42 \%$ dari bayi yang berusia di bawah 6 bulan yang mendapatkan ASI eksklusif. Pada saat anak-anak mendekati ulang tahunnya yang ke dua, hanya 55\% yang masih diberi ASI. Jika dibandingkan dengan target WHO yang mencapai 50\%, maka angka tersebut masihlah jauh dari target. Berdasarkan data yang dikumpulkan International Baby Food Action Network (IBFAN) 2014, Indonesia menduduki peringkat ke tiga terbawah dari 51 negara di dunia yang mengikuti penilaian status kebijakan dan program pemberian makan bayi dan anak (InfantYoung Child Feeding) (Ikatan Bidan Indonesia, 2018 dalam Silawati, 2020). Cakupan ASI eksklusif di Indonesia 38\% dan di Kabupaten Sleman DIY sebesar 32,43\% (Dinas Kesehatan Kabupaten Sleman, 2018). Kementrian Kesehatan Republik Indonesia menargetkan cakupan ASI eksklusif sebesar 80\% (Kementrian Kesehatan RI, 2019). Saat ini peran pemerintah, dukungan masyarakat terhadap program ASI eksklusif masih belum optimal, pemahaman ASI eksklusif sebagian masyarakat masih belum benar.

ASI mengandung semua bahan yang diperlukan bayi, mudah dicerna, memberi perlindungan terhadap infeksi, selalu segar, bersih dan siap untuk diminum. Menyusui adalah cara optimal dalam memberikan kebutuhan nutrisi, imunologi dan psikososial dalam mengasuh bayi. Menurut (Roesli, 2011) ASI stadium I dari hari pertama sampai hari keempat adalah kolostrum. Kolostrum sangat penting bagi pertahanan tubuh bayi karena kolostrum merupakan imunisasi pertama bagi bayi. Kolostrum membantu mengeluarkan meconium dari usus bayi sehingga mukosa usus bayi baru lahir segera bersih dan siap menerima ASI.

Colin dan Scott (2002) dalam penelitiannya yang dilakukan di Australia menjelaskan bahwa $29 \%$ ibu post partum berhenti menyusui karena produksi ASI berkurang. Kenyataan di lapangan menunjukkan produksi dan ejeksi ASI yang sedikit pada harihari pertama setelah melahirkan menjadi kendala dalam memberikan ASI secara dini. Menurut Cox (2006) ibu yang tidak dapat menyusui pada hari-hari pertama disebabkan oleh kecemasan dan ketakutan ibu akan kurangnya produksi ASI serta kurangnya pengetahuan ibu tentang proses menyusui. Kecemasan dan ketakutan yang dialami ibu tersebut akan menyebabkan penurunan hormon oksitosin sehingga ASI tidak dapat keluar segera setelah melahirkan, sehingga akhirnya ibu memutuskan untuk memberikan susu formula pada bayinya (Lestari, dkk., 2018). Alasan lain yang diungkapkan ibu-ibu berkaitan dengan kurang berhasilnya dalam program ASI eksklusif ini adalah ibu merasa bahwa ASInya tidak cukup, ibu bekerja dan ibu merasa kesulitan dalam pemberian ASI. Pada hari-hari pertama setelah melahirkan biasanya ibu mengalami pengeluaran ASI yang cenderung sedikit. Kemudian kebanyakan ibu setelah mengetahui ASInya keluar sedikit langsung memberikan susu formula. Padahal proses menghisap awal inilah yang penting untuk merangsang produksi ASI.

Salah satu faktor seorang ibu tidak dapat memberikan ASI eksklusif pada bayinya yaitu pengeluaran ASI yang tidak lancar. Pengeluaran ASI yang tidak lancar ini dapat distimulasi dengan kombinasi massage nape dan teknik marmet. Teknik marmet memberikan efek relaks dan juga mengaktifkan kembali reflek keluarnya air susu sehingga air susu mulai menetes. Teknik ini merupakan teknik untuk menegeluarkan ASI yaitu dengan cara memijat dan memerah ASI. Selain itu juga terdapat teknik yang memiliki dasar stimulasi oksitosin melalui massage nape untuk merangsang produksi ASI. Pijat punggung ini dilakukan untuk merangsang reflek oksitosin atau reflek let down. Massage nape dilakukan dengan cara memijat daerah punggung sepanjang ke dua sisi tulang belakang. Adanya kombinasi massage nape dan teknik marmet diharapkan mampu mempercepat proses pengeluaran ASI dan mngoptimalkan pengeluaran ASI agar bayi mendapatkan nutrisi yang terbaik.

Teknik memerah ASI yang dianjurkan adalah dengan mempergunakan tangan dan jari karena praktis, efektif dan efisien dibandingkan dengan menggunakan pompa. Hal ini merupakan salah satu usaha untuk merangsang hormon 
prolaktin dan oksitosin pada ibu setelah melahirkan (Mardiyaningsih \& Sabri, 2011). Hasil penelitian (Nurchayati, 2012) mengatakan bahwa terdapat manfaat massage tengkuk terhadap pengeluaran ASI pada ibu nifas. Massage tengkuk juga terbukti dalam meningkatkan jumlah air susu ibu nifas hari pertama sampai hari ketiga sehingga produksi air susu ibu lancer dan bayi dapat ASI secara maksimal (Pratiwi, 2019).

Berdasarkan studi pendahuluan di Wilayah Kerja Puskesmas Ngaglik II Sleman didapatkan hasil bahwa dari 10 ibu post partum yang ditemui, 7 ibu tidak mengeluarkan ASI pada hari pertama atau kedua. Kemudian dari hasil wawancara yang dilakukan, ibu menyampaiakn merasa cemas saat ASInya tidak keluar dan takut bayinya tidak mendapatkan nutrisi dengan maksimal yang akhirnya, mereka langsung memilih susu formula untuk memenuhi nutrisi pada bayinya.

Berdasarkan uraian di atas, peneliti tertarik melakukan penelitian tentang kombinasi massage nape dan teknik marmet terhadap Percepatan Pengeluaran ASI pada ibu post partum di wilayah kerja Puskesmas Ngaglik II Sleman Yogyakarta.

\section{METODE}

Penelitian ini merupakan penelitian kuantitatif, jenis penelitian quasy experimental dengan pendekatan post-test. Penelitian ini dilakukan di wilayah kerja Puskesmas Ngaglik II Sleman Yogyakarta. Teknik sampling yang digunakan dalam penelitian ini adalah metode purposive sampling dengan jumlah sampel 30 yang terbagi menjadi 2, antara responden yang diberikan intervensi dengan yang tidak diberikan intervensi.

Instrumen yang digunakan adalah lembar observasi massage nape dan lembar observasi pengeluaran ASI. Analisis bivariat dalam penelitian ini menggunakan Mann Whitney Test untuk membandingkan pengukuran dua kelompok yang berbeda dengan tidak melihat normalitasnya. Adapun untuk penelitian ini sudah memenuhi syarat layak etik dengan nomor sertifikat layak etik sebagai berikut: LB.01.01/KE-01/XXXV/766/2018

\section{HASIL}

UPT Puskesmas Ngaglik II merupakan salah satu yang tersebar di wilayah Kabupaten
Sleman Yogyakarta. Puskesmas Ngaglik II terletak di wilayah bagian tengah kabupaten Sleman. UPT Puskesmas Ngaglik II menempati lokasi di Dusun Kayunan, Desa Donoharjo, Kecamatan Ngaglik, Kabupaten Sleman. Dari penelitian, didapatkan hasil sebagai berikut:

Tabel 1. Distribusi Frekuensi Karakteristik Kelompok Responden Intervensi

\begin{tabular}{lrr}
\hline \multicolumn{1}{c}{ Karakteristik } & Frekuensi & $\%$ \\
\hline Umur & & \\
$<20$ tahun & 0 & 0 \\
$20-35$ tahun & 12 & 80 \\
$>35$ tahun & 3 & 20 \\
Pekerjaan & & \\
Tidak Bekerja & 10 & 66,7 \\
Bekerja & 5 & 33,3 \\
Pend.Terakhir & & \\
Rendah (<SMA) & 2 & 13,3 \\
Tinggi ( $\geq$ SMA) & 13 & 86,7 \\
Paritas & & \\
Primipara & 5 & 33,3 \\
Multipara & 9 & 60 \\
Grandemultipara & 1 & 6,7 \\
Percepatan & & \\
Pengeluaran ASI & & \\
Lambat $(\geq 4$ hari) & 0 & 0 \\
Normal $(2-3$ hari $)$ & 6 & 40 \\
Cepat (hari ke 1$)$ & 9 & 60 \\
\hline
\end{tabular}

Berdasarkan tabel 1 menunjukkan bahwa mayoritas umur ibu berada pada usia reproduksi sehat sebesar $80 \%$, dan $20 \%$ saja ibu yang dalam kategori faktor resiko. Sedangkan pekerjaan ibu mayoritas tidak bekerja $(66,7 \%)$, Pendidikan terakhir mayoritas tinggi sebesar $(86,7 \%)$, Paritas mayoritas multipara $(60 \%)$ dan percepatan pengeluaran ASI mayoritas cepat sebesar $60 \%$.

Tabel 2. Distribusi Frekuensi Karakteristik Kelompok Responden Kontrol

\begin{tabular}{lrr}
\hline \multicolumn{1}{c}{ Karakteristik } & Frekuensi & \% \\
\hline Umur & & \\
$<20$ tahun & 0 & 0 \\
$20-35$ tahun & 14 & 93,3 \\
$>35$ tahun & 1 & 6,7 \\
Pekerjaan & & \\
Tidak Bekerja & 10 & 66,7 \\
Bekerja & 5 & 33,3 \\
Pend.Terakhir & & \\
Rendah (<SMA) & 2 & 13,3 \\
Tinggi (( $\geq$ SMA) & 13 & 86,7 \\
Paritas & & \\
Primipara & 4 & 26,7 \\
Multipara & 11 & 73,3 \\
Grandemultipara & 0 & 0 \\
Percepatan & & \\
Pengeluaran ASI & & \\
Lambat $(\geq 4$ hari) & 1 & 6,7 \\
Normal (2-3 hari) & 13 & 86,7 \\
Cepat (hari ke 1) & 1 & 6,7 \\
\hline
\end{tabular}


Berdasarkan tabel 2 menunjukkan bahwa mayoritas umur ibu berada pada usia reproduksi sehat sebasar $93,3 \%$, dan $6,7 \%$ saja ibu yang dalam kategori faktor resiko. Sedangkan pekerjaan ibu mayoritas tidak bekerja $(66,7 \%)$,
Pendidikan terakhir mayoritas tinggi sebesar (86,7\%), Paritas mayoritas multipara $(73,3 \%)$ dan percepatan pengeluaran ASI mayoritas cepat sebesar $86,7 \%$

Tabel 3. Hasil Uji Normalitas Data

\begin{tabular}{|c|c|c|c|c|c|}
\hline \multirow{5}{*}{$\begin{array}{c}\text { Pengeluaran } \\
\text { ASI }\end{array}$} & \multirow{2}{*}{ Kelompok } & \multicolumn{3}{|c|}{ Shapiro Wilk } & \multirow{2}{*}{ Kesimpulan } \\
\hline & & Statistic & df & sig & \\
\hline & Tidak diberi & 0,433 & 15 & 0,0 & Tidak \\
\hline & Intervensi & & & & Normal \\
\hline & Diberi & 0,385 & 15 & 0,0 & Tidak \\
\hline
\end{tabular}

Analisis didasarkan pada nilai probabilitas (Sig) yang dibandingkan dengan derajat kebebasan 0,05. Dari table diatas diperoleh hasil bahwa untuk uji normalitas dengan menggunakan Shapiro-Wilk adalah sebagai berikut: selisish/beda pengeluaran ASI pada kelompok yang tidak diberikan intervensi adalah 0,000 dan selisih/beda pengeluaran ASI pada kelompk yang diberikan intervensi adalah 0,00. Untuk melakukan pengujian dari hasil output tersebut, ada beberapa ketentuan yang menjadi patokan. Berikut ini adalah langkah dan ketentuan uji normalitas. Kriteria keputusan :

a. Nilai Sig, atau probabilitas <0,05 (Distribusi tidak normal)

b. Nilai Sig, atau probabilitas $>0,05$ (Distribusi normal)

Maka dapat disimpulkan dari 2 beda/selisih yang telah dilakukan uji normalitas, keduanya berditribusi tidak normal. Karena nilai sig adalah $0,00<$ dari 0,05 . Berdasarkan uji hasil normalitas, karena distribusi data keduanya tidak normal, maka uji $\mathrm{T}$ tidak dapat dilakukan. Selanjutnya dipilih uji yang sesuai yaitu Wilcoxon Mann Whitney U Test.

Tabel 4. Hasil Uji Wilcoxon Mann Whitney $U$ Test

\begin{tabular}{lr}
\hline \multicolumn{1}{c}{ Pent } \\
\hline Mann-Whitney $U$ & 49.500 \\
Wilcoxon $W$ & 169.500 \\
Z & -3.102 \\
Asymp.Sig (2-tailed) & 0,002 \\
Exact Sig $(2 *(1$-tailed Sig) $)$ & 0,008 \\
\hline
\end{tabular}

Hasil analisis statistik Mann Whitney menunjukkan mean rank kombinasi massage nape dan tekhnik marmet sebesar 19,70 dan mean rank kontrol sebesar 11,30, yang berarti terdapat pebedaan rata-rata anatar dua kelompok tersebut. Sedangkan untuk nilai signifikansi 2tailed adalah $0,002<0,05$ yang berarti $\mathrm{Ha}$ diterima, dengan demikian terdapat perbedaan bermakna antara kelompok perlakuan dan kelompok kontrol. Setelah pemberian kombinasi massage nape dan teknik marmet setalh melahirkan, terdapat perbedaan hasil antara pengeluaran ASI pada kelompok intervensi dan kelompok kontrol dengan signifikasi $(0,002)$.

\section{PEMBAHASAN}

Berdasarkan hasil penelitian yang dilakukan terhadap ibu post partum yang diberikan perlakuan kombinasi massage nape dan teknik marmet didapatkan hasil bahwa seluruh responden (100\%) yaitu sebanyak $60 \%$ percepatan pengeluaran ASI nya dalam kategori cepat dan $40 \%$ sisanya adalah normal. Hasil uji statistik diperoleh $p$-value 0,002 artinya $p<a l p a$ $(0,05)$ berarti terdapat perbedaan yang bermakna antara kelompok perlakuan dan kelompok kontrol terhadap percepatan pengeluaran ASI pada ibu post partum.

Hasil penelitian ini sejalan dengan (Sloane, 2003) yang menyatakan peranan massage nape (pemijatan tengkuk) mampu memperlancar pengeluaran ASI yang mungkin pada awal pengeluarannya sedikit sehingga mampu mencukupi kebutuhan nutrisi bayi. Proses awal pemijatan pada otot semispinalis memperlancar aliran darah menuju hipofisis melalui arteri hipofisis interior dan superior. Setelah rangsangan diterima hipofisis akan mengeluarkan hormone endorphin yang akan membuat ibu nyaman saat menyusui. Pada perasaan yang nyaman inilah proses pengeluaran prolactin oleh hipofisis akan berlangsung (dibantu dengan hisapan bayi). Sifat otot semispinalis mampu menimbulkan kontraksi simultan. Dengan kontraksi simultan inilah sinyal dari hipofisis akan dengan cepat diterima hipotalamus untuk mengeluarkan oksitosin yang berguna pada proses involusio uteri dan membantu menekan duktus untuk mengeluarkan 
ASI. Roesli (2011) juga menyebutkan bahwa impuls neural dari pemijatan tengkuk yang terbentuk dari rangsang i merupakan stimulus primer bagi pelepasan oksitosin. Sejalan dengan yang disampaikan oleh Soetjiningsih (2009) yang menyebutkan bahwa faktro-faktor penghambat efek reflex let down terdapat pada ibu dan bayinya. Adapun salah satu faktor dari ibu adalah keadaan psikologis yang tidak stabil. Artinya bila ada stres dari ibu menyusui maka akan terjadi blockade dari reflex let down. Ini disebabkan oleh karena adanya pelepasan dari adrenalin (epineprin) yang menyebabkan vasokontriksi dari pembuluh darah eleoli sehingga oksitosin kurang mencapai target organ mioepitelium. Akibat tidak sempurnanya reflex let down maka akan terjadi penumpukan air susu di dalam alveoli. Karena reflex down tidak sempurna bayi yang haus menjadi tidak puas. Ketidakpuasan ini akan menjadi tambahan stress bagi ibu. Hal ini jelas akan mempengaruhi proses pengeluaran ASI (Soetjiningsih, 2009).

Keberhasilan dalam pemberian kombinasi massage nape dan teknik marmet terhadap pengeluaran ASI juga diperkuat karena keadaan psikologis ibu cenderung lebih rileks. Teknik akupresur atau pijat yang dilakukan dapat mengurangi sensasi nyeri melalui peningkatan endorphin, yaitu hormon yang mampu menghadirkan rileks pada tubuh secara alami, memblok reseptor yeri ke otak sehingga dapat membantu pengeluaran hormon oksitosin yang dapat merangsang pengeluaran ASI (Safitri, dan Susilaningsih, 2015). Pemijatan tengkuk dan punggung memberikan kontribusi yang besar bagi ibu nifas (Dhanio, dkk., 2020).

Penelitian lain yang sejalan dengan massage nape adalah Sebayang (2017) dengan hasil penelitiannya terdapat peningkatan jumlah volume kolostrum ASI sesudah melakukan massage tengkuk dan massage payudara dengan kompres hangat. Berdasarkan hasil penelitian Pratiwi (2019) dengan judul pengaruh massage tengkuk terhadap peningkatan jumlah air susu ibu nifas dari hari pertama sampai hari ketiga, sejalan dengan analisanya data perbandingan eksperimen dan kelompok pembanding didapatkan $p$-value 0,000 , artinya massage tengkuk lebih efektif dari pada massage otot pectoralis dalam meningkatkan pengeluaran ASI pada ibu nifas hari pertama sampai hari ketiga.

Hasil penelitian Widiastuti, dkk (2015) juga menyebutkan bahwa pemberian perlakuan teknik marmet menyebabkan pengeluaran ASI lebih lancar. Dalam penelitiannya menyebutkan bahwa gambaran kelancaran ASI, kelompok marmet pada beberapa kriteria memiliki persentase yang lebih tinggi bila dibandingkan dengan kelompok yang diberikan massage payudara. Teknik marmet sendiri merupakan kombinasi memijat dan memompa payudara yang dapat meningkatkan pengeluaran hormon prolaktin dan oksitosin. Menjelang akhir kehamilan prolaktin memegang peranan membuat kolostrum, namun jumlah kolostrum terbatas karena aktifitas prolaktin dihambat oleh estrogen dan progesteron yang kadarnya memang tinggi. Setelah lepasnya plasenta dan kurang berfungsinya korpusluteum maka estrogen dan progesteron sangat berkurang, ditambah isapan bayi yang merangsang puting susu dan payudara. Rangsangan dilanjutkan ke hipotalamus melalui medulla spinalis dan mesensephalon. Hipotalamus menekan pengeluaran yang memacu sekresi prolaktin. Hormon ini merangsang sel-sel alveoli yang berfungsi untuk membuat air susu. Jadi disini jelas bahwa proses fisiologis teknik marmet dapat merangsang pengelauaran ASI lebih cepat dan banyak. Debby (2014) dalam penelitiannya yang berjudul pengaruh teknik marmet terhadap produksi ASI pada ibu nifas di RSUD DR. Wahidin Sudiro Husodo ota Mojokerto, didapatkan pada kelompok perlakuan 19 orang responden produksi ASInya lancar dan pada kelompok kontrol sebagian besar mengalami produksi ASInya tidak lancar (12 responden). Hasil uji Mann Withney diperoleh hasil nilai signifikansi $p$-value $=0,005$ dengan tingkat kemaknaan 0,05 . Oleh karena itu $0,005<0,05$, yang artinya ada pengaruh teknik marmet terhadap produksi ASI pada ibu nifas di RSUD Dr. Wahidin Sudiro Husodo Kota Mojokerto.

Hasil sejalan juga disampaikan oleh Ulfah, (2013), berdasarkan penelitiannya yang menunjukkan bahwa pada kelompok perlakuan sebelum diberikan teknik marmet pengeluaran ASI tidak lancar sebanyak delapan responden dan pengeluaran ASI lancar sebanyak tujuh responden. Sedangkan setelah pemberian teknik marmet, didapatkan bahwa seluruh responden sejumlah 15 responden pada kelompok perlakuan pengeluaran ASI lancar. Kesimpulannya adalah pemberian teknik marmet pada ibu post partum efektif terhadap kelancaran ASI. Seperti yang telah dijelaskan sebelumnya bahwa teknik marmet akan merangsang pembentukan prolaktin sehingga menstimulasi hormon oksitosin yang akan berperan sebagai pengeluaran ASI. Bersamaan dengan pembentukan prolaktin oleh andenohipofisis, rangsangan akan dilanjutkan ke neuron hipofise yang kemudian dikeluakan oksitosin. Melalui darah, hormon ini diangkat menuju uterus yang dapat menimbulkan 
kontraksi uterus sehingga terjadi involusi dari organ tersebut. Oksitosin yang sampai alveoli akan mempengaruhi sel mioepitelium yang dilanjutkan dengan pengeluaran ASI (Soetjiningsih, 2009).

Pengeluaran ASI di bawah kendali neuroendokrin, rangsangan taktil pada payudara juga merangsang oksitosin, yang menyebabkan pemendekan sel mioepitel (Myles, 2015). Pijat sangat bermanfaat bagi orang yang mengalami kelelahan berlebihan efek pijatan sangat nyaman, sedative dan mampu memberikan rangsangan pada syaraf serta meningkatkan aktifitas otot (Trisnowiyano, 2014). Massage tengkuk memberikan relaksasi pada ibu nifas saat menyusui, dalam keadaan rileks hipotalamus akan mengeluarkan hormon endorfin dimana hormon endorphin memberikan efek tenang pada iibu sehingga ibu yang menyusui mampu mempertahankan produksi ASI sehingga bisa mencukupi bagi bayi. dengan adanya pijatan maka merangsang jaringan-jaringan saraf, mengaktifkan saraf simpatis dan saraf parasimpatis, pijatan tersebut merangsang hipotalamus dan memacu hipofise anterior untuk mengeluarkan hormon prolaktin dan oksitoksin ke dalam darah. Dimana hormon oksitosin berperan dalam meningkatkan pengeluaran ASI. Maasage tengkuk dapat mengurangi nyeri ibu menyusui dan membantu meredam stres emosional, dengan pijatan tengkuk merangsang keluarnya endorfin yang menenangkan sehingga reflek oksitosin dan prolaktin menjadi lancar. Prolaktin menstimulus produksi ASI, tetapi di perlukan hormon lain untuk mengeluarkan air susu ke permukaan puting susu. Stimulasi mekanoreseptor areola akan mengaktifasi jalur saraf yang naik ke nukleus paraventrikel dan nukleus supraoptik hipotalamus, melalui nervus sevikalis lateral batang otak. jalur syaraf ini mengeksitasi neoron magnoseluler untuk mengekresi oksitosin secara pulsatil kedalam darah dalam interval 10-20 menit (Ward, P. . J., Clarke, R. W., \& Linden, 2007). Berdasarkan uraian di atas, apabila dilihat dalam struktur anatomi massage tengkuk langsung menghantarkan rangsangan ke hipotalamus melalui nervus sevikalis lateral batang otak.

Berdasarkan pengamatan peneliti adanya kombinasi dari massage nape dan teknik marmet yang diberikan kepada ibu post partum menjadi salah satu faktor yang sangat signifikan terhadap percepatan pengeluaran ASI pada ibu post partum. Hal ini dapat tergambar dari mekanisme massage nape yang dilakukan melalui pemijatan pada bagian tengkuk dengan tujuan merileksasikan otot yang secara langsung dapat memberikan efek rileks terhadap ibu post partum sehingga memicu hormon oksitosin dalam pengeluaran ASI. Adapun untuk teknik marmet merupakan kombinasi cara memerah ASI dan memijat payudara sehingga refleks ASI dapat optimal. Teknik memerah ASI dengan cara marmet bertujuan untuk mengosongkan ASI dari sinus laktiferus yang terletak di bawah areola sehingga diharapkan dengan mengosongkan ASI pada sinus laktiferus akan merangsang pengeluaran prolaktin. Pengeluaran hormon prolaktin diharapkan akan merangsang mammary alveoli untuk memperoduksi ASI. Semakin banyak ASI dikeluarkan atau dikosongkan dari payudara akan semakin baik produksi ASI dipayudara. Artinya kedua perlakuan antara massage nape dan teknik merupakan salah satu cara yang tepat untuk menstimulasi pengeluaran ASI pada ibu post partum agar lebih cepat keluar dan pengeluarannya optimal.

Menurut Soetjiningsih (2009) hubungan antara hipotalamus dan hipofise akan mengatur kadar prolaktin dan oksitosin dalam darah. Hormon-hormon ini sangat perlu untuk pengeluaran permulaan dan pemeliharaan penyediaan air susu selama menyusui. Proses menyusui memerlukan pembuatan dan pengeluaran air susu dari alveoli ke sistem duktus. Bila susu tidak dikeluarkan akan mengakibatkan berkurangnya sirkulasi darah kapiler yang menyebabkan terlambatnya proses menyusui. Pengeluaran oksitosin ternyata di samping dipengaruhi oleh isapan bayi juga dipengaruhi oleh suatu reseptor yang terletak pada sistem duktus. Bila duktus melebar atau menjadi lunak maka secara reflektoris dikeluarkan oksitosin oleh hipofise yang berperan untuk memeras keluar air susu dari alveoli. Jadi peranan prolaktin dan oksitosin mutlak perlu selama proses menyusui.

Melihat manfaat massage nape dan teknik marmet yang sangat besar kontribusinya terhadap pengeluaran ASI, maka wajar sekali ketika kedua teknik tersebut di terapkan kepada ibu post partum dan menghasilkan percepatan ASI yang cepat dari biasanya.

\section{SIMPULAN}

Kombinasi massage nape dan teknik marmet berpengaruh terhadap percepatan pengeluaran ASI. 


\section{DAFTAR PUSTAKA}

Colin, W.B., \& Scott, J.A. (2002). Breastfeeding: reasons for starting, reasons for stopping and problems along the way. Australia: School of Public Health.

Cox, S. (2006). Breastfeeding with confi dence: Panduan untuk belajar menyusui dengan percaya diri. (Gracinia, Penerjemah.). Jakarta: Gramedia

Dhanio, Y. W., Rafika, R., \& Batjo, S. H. (2020). Perbedaan Kombinasi Massage Tengkuk Dan Massage Oksitosin Dengan Massage Oksitosin Terhadap Waktu Pengeluaran Asi Pada Ibu Post Partum. Media Kesehatan Politeknik Kesehatan Makassar, 15(1), 77-86.

Dinas Kesehatan Kabupaten Sleman. (2018). Profil Kesehatan Kabupaten Sleman. https://dinkes.slemankab.go.id/wpcontent/uploads/2018/09/PROFILKESEHATAN-2018-1.pdf

Kementrian Kesehatan RI. (2019). Profil Kesehatan Indonesia 2018 Kemenkes RI. Jakarta.

Lestari, L., Nurul, M., \& Admini. (2018). Peningkatan Pengeluaran Asi Dengan Kombinasi Pijat Oksitosin Dan Teknik Marmet Pada Ibu Post Partum (Literatur Review). Jurnal Kebidanan, 8(2), 120-129. http://ejournal.poltekkes-

smg.ac.id/ojs/index.php/jurkeb/article/view 13741

Mardiyaningsih, E., \& Sabri, L. (2011). Efektifitas Kombinasi Teknik Marmet Dan Pijat Oksitosin Terhadap Produksi Asi Ibu Post Seksio Di Rumah Sakit Wilayah Jawa Tengah. Soedirman Journal of Nursing, $6(1)$, $31-38$. https://doi.org/10.20884/1.jks.2011.6.1.321

Myles. (2015). Buku Ajar Kebidanan:Myles Textbook For Midwives. Jakarta: EGC.

Ningsih, D.I. (2014). Pengaruh Teknik Marmet terhadap Produksi ASI pada Ibu Nifas di RSUD DR. Mojokerto. [Karya Tulis Ilmiah]. Surabaya: RSUD Dr. Wahidin Sudiro.

Nurchayati. (2012). Manfaat Massaging Nape (Pemijatan Tengkuk) Terhadap Pengeluaran ASI Pada Ibu Nifas di RSUD Cilacap. [Karya Tulis Ilmiah]. Akademi Kebidanan Graha Mandiri Cilacap.

Pusat Data dan Informasi Kementrian Kesehatan RI. (2014). Situasi dan Analisis ASI
Eksklusif 2014. Jakarta : Kementrian Kesehatan RI

Pratiwi, F. (2019). Efektifitas Massage Tengkuk Terhadap Peningkatan Jumlah Air Susu Ibu Nifas Hari Pertama Sampai Hari Ketiga Di Puskesmas Wilayah Bantul. Mikki (Majalah Ilmu Keperawatan Dan Kesehatan Indonesia), 8(2). http://jurnal.stikeswirahusada.ac.id/mikki/a rticle/view/214/154

Roesli, U. (2011). Inisiasi Menyusui Dini Plus ASI Eksklusif. Pustaka Bunda.

Ulfah, RRM. (2013). Efektivitas Pemberian Teknik Marmet Terhadap Pengeluaran ASI pada Ibu Menyusui 0-6 bulan di Wilayah Kerja Puskesmas Arjasa Kabupaten Jember. UNEJ. http://repository.unej.ac.id/handle /123456789/9987

Sebayang, W. B. R. (2017). Manfaat Massase Tengkuk dan Kompres Hangat Payudara terhadap Pengeluaran Kolostrum Asi pada Ibu Post Partum di Klinik Pratama Rosni Alizar Medan Tahun 2017. Jurnal Ilmiah Kebidanan Imelda, 3(2), 267-270. http://jurnal.uimedan.ac.id/index.php/JUR NALKEBIDANAN/article/view/138/141

Silawati, V., \& Murnita, E. (2020). Efektivitas Teh Sibangun bangun Terhadap Volume ASI Pada Ibu Post SC Di Rumah Sakit Marinir Cilandak Tahun 2019. Journal for Quality in Women's Health, 3(2), 140-145.

Sloane, E. (2003). Anatomi dan Fisiologi untuk Pemula. Jakarta: EGC.

Soetjiningsih. (2009). ASI Petunjuk Untuk Tenaga Kesehatan. Jakarta: EGC.

Safitri, WN., Susilaningsih, A. P. (2015). Pijat Punggung dan Percepatan Pengeluaran ASI Pada Ibu Post Partum. Jurnal Informasi Kesehatan Indonesia, 1(2).

Trisnowiyano. (2014). Ketrampilan Dasar Massage. Nuha Medika.

Ward, P. . J., Clarke, R. W., \& Linden, R. W. (2007). At a Glance Fisiologi : Physiologi at a Galance. (A. Safitri \& R. Astikawati, $E d s$.). Jakarta: Erlangga.

Widiastuti, A., Arifah, S., \& Rachmawati, W. R. (2015). Pengaruh Teknik Marmet terhadap Kelancaran Air Susu Ibu dan Kenaikan Berat Badan Bayi. Kesmas: National Public Health Journal, 9(4). https://doi.org/10.21109/kesmas.v9i4.737 